Gut, 1986, 27, S1, 76-80

\title{
Enteral nutrition in inflammatory bowel disease
}

\author{
M A GASSUll, A ABAD, E CABRÉ, F GONZÁleZ-HuiX, J J Giné, AND C DOLZ \\ From the Department of Gastroenterology, Hospital de Bellvitge "Prínceps d'Espanya" L'Hospitalet, \\ Barcelona, Spain
}

Summary To assess the effect of the addition of enteral tube feeding with polymeric diets to the standard treatment of acute attacks of inflammatory bowel disease a total of 43 patients admitted to hospital (23 with Crohn's disease and 20 with ulcerative colitis) were studied retrospectively. Total enteral nutrition was given to 26 as the sole nutritional supply and to 17 in conjunction with a normal ward diet, when appropriate, according to the severity of attack (control group). Nutritional state was assessed and classified in all patients at admission and at the end of the study, by measuring the triceps skinfold thickness, mid arm muscle circumference, and serum albumin concentration as representative of body fat, muscle protein, and visceral protein, respectively. At admission the three nutritional variables were not statistically different between the groups.

There was a significantly positive effect on mid arm muscle circumference in patients on total enteral nutrition compared with the control group, but there was no effect on either triceps skinfold thickness or serum albumin concentration. The percentage of subjects requiring intravenous albumin infusion, however, was significantly less in the group fed enterally than in the control group. In addition, fewer patients in the group fed enterally required surgical treatment compared with the control group, despite the fact that one of the criteria for starting enteral nutritional support was the expectancy that surgery would be needed. Total enteral nutrition was well tolerated and no major side effects arose during its use in patients with acute exacerbations of inflammatory bowel disease.

One feature commonly found in all varieties of inflammatory bowel disease is malnutrition. ${ }^{1-4}$ Protein energy malnutrition is most commonly seen in those patients requiring admission, and, indeed, many patients with low grade chronic inflammation may have no discernible nutritional deficit. Several factors can lead to protein energy malnutrition. ${ }^{5}$ These include a poor nutritional intake, malabsorption - due either to active disease, or previous resection, or bypass - as well as protein losses through the colon or small bowel. ${ }^{6}$ Rates of body protein sythesis and breakdown have both been found to increase in direct proportion to disease activity. $^{7}$

During the past decade interest in the nutritional support of patients with inflammatory bowel disease has focused on the use of parenteral rather than enteral nutrition. Both Clark $^{8}$ and Matuchansky ${ }^{9}$ have critically reviewed the efficacy of parenteral nutrition in inflammatory bowel disease.

Correspondence to: Dr M A Gassull, Department of Gastroenterology. 19th Floor. Hospital de Bellvitge "Prínceps d'Espanya" L'Hospitalet, Barcelona. Catalunya, Spain.
One of the most important reasons for not using the enteral route in inflammatory bowel disease has been the fact that many authors have presumed that clinical benefits are likely to occur as a consequence of bowel rest and have therefore favoured the use of the parenteral route. ${ }^{1011}$

On the basis, however, that Crohn's disease might comprise two main components, an underlying predisposition to ulceration of the gut, and a secondary immunological reaction to the passage of large amounts of foreign antigens through the damaged gut wall, Levi et al fed an elemental diet to patients with Crohn's disease in an attempt to treat the secondary aspect. ${ }^{12} 13$ The results of their uncontrolled and controlled trials have been encouraging. Others have also administered elemental diets to patients with inflammatory bowel disease. $^{14-16}$ In nutritional terms, though, the results were far from satisfactory, principally because of the limited amount of nitrogen given and the high osmolality of the diets administered.

In this study we analysed data obtained from 43 patients with acute exacerbations of inflammatory 
bowel disease admitted to our unit between 1981 and 1985. Emphasis was placed on the evaluation of nutritional state, particularly in respect of any positive effect to be derived from nutritional support. In the event of nutritional support being indicated it was provided by the enteral route.

\section{Patients and methods}

Twenty three patients with Crohn's disease and 20 with ulcerative colitis were included in the study. All patients were evaluated nutritionally using the triceps skinfold thickness, mid arm muscle circumference, and serum albumin concentration as representative means of assessing the fat, muscle protein, and visceral protein nutritional components. Values for each variable were expressed as a percentage of the mean obtained from a large sample of a healthy population served by our hospital. ${ }^{17}$ On the basis of these measurements patients were classified into one of eight nutritional types as previously described. ${ }^{17}$

\section{NUTRITIONAL SUPPORT}

Enteral nutrition was administered nasogastrically ${ }^{18}$ to 26 patients in conjunction with appropriate and standard treatment. In 17 patients treatment was prescribed in conjunction with a normal ward diet (when appropriate). The decision to administer enteral nutrition was made independently of the nutritional evaluation and was based on the severity of attack, the general state of the patients (when surgery was envisaged as a therapeutic possibility), and whether the technique of enteral feeding was available at the time of the patient's admission. Seventeen patients did not receive enteral nutrition either because it was not thought to be clinically indicated or because the technique was not available at the time.

The mean caloric and nitrogen intakes in these patients receiving enteral feeding were $58 \cdot 1 \pm 2 \cdot 5$ $\mathrm{kcal} / \mathrm{kg} / \mathrm{day}$ and $0.37 \pm 0 \cdot 10 \mathrm{~g}$ nitrogen $/ \mathrm{kg} /$ day, respectively. Two types of polymeric formula diets were prescribed, one with a non-protein calorie: nitrogen ratio of 165 and the other with a ratio of 102. The 43 patients were studied during the course of 61 periods of hospital stay (35 with enteral feeding and 26 without).

\section{Results}

QUALITATIVE ASPECTS OF PROTEIN ENERGY MALNUTRITION

On admission $92.3 \%$ of the patients who received enteral nutrition were considered to have evidence of protein energy malnutrition. This compared with an incidence of $76.5 \%$ in those who later received only a normal ward diet. The Figure shows that mixed malnutrition was the predominant nutritional type $(61.6 \%$ of those who received enteral nutrition, $47 \cdot 1 \%$ of those who did not). Kwashiorkor like malnutrition was equally distributed $(23 \%)$ in both groups.

The predominant nutritional type in the patients with Crohn's disease in both groups was mixed malnutrition, whereas the patients with ulcerative colitis had either the mixed type or kwashiorkor like malnutrition.

On discharge $29.9 \%$ of the patients who received enteral nutrition were considered to be well nourished, an increase of $19 \cdot 2 \%$. In contrast, the incidence of protein energy malnutrition actually increased from 76.5 to $88.2 \%$ in the group of patients who were not fed enterally. As can be seen from the Figure, this was largely due to an increase in the incidence of marasmus type of malnutrition. In the patients who received enteral nutrition there was a sharp reduction (from $61.6 \%$ to $23.1 \%$ ) in the incidence of the mixed type of malnutrition.

Enteral nutrition seemed to have its major qualitative impact on nutritional state in patients with ulcerative colitis. While all of the patients who subsequently received enteral nutrition were considered to have evidence of protein energy malnutrition on admission a third were well nourished on discharge.

QUANTITATIVE ASPECTS OF PROTEIN ENERGY

MALNUTRITION

On admission there were no major differences in any of the three nutritional variables triceps skinfold thickness, mid arm muscle circumference, and serum albumin concentration between patients who subsequently received enteral nutrition and those who did not. Similarly, there were no major differences in any of the variables in patients admitted with Crohn's disease compared with those admitted with ulcerative colitis.

On discharge there was a significant deterioration in mid arm muscle circumference in those patients who did not receive enteral nutrition compared with those who did $(\mathrm{p}<0.0005$; paired $t$ test) (Table). Enteral nutrition had no effect on triceps skinfold thickness and serum albumin concentration. A significantly greater number of patients who did not receive enteral nutrition, however, required intravenous infusions of albumin $(64.7 \%)$ than those who were fed enterally $\left(21.4 \%, p<0 \cdot 01, \chi^{2}\right.$ test $)$.

In 19 patients with inflammatory bowel disease studied on admission and just before surgery enteral nutrition had a significantly beneficial effect on triceps skinfold thickness $(p<0.025)$ but not on mid 

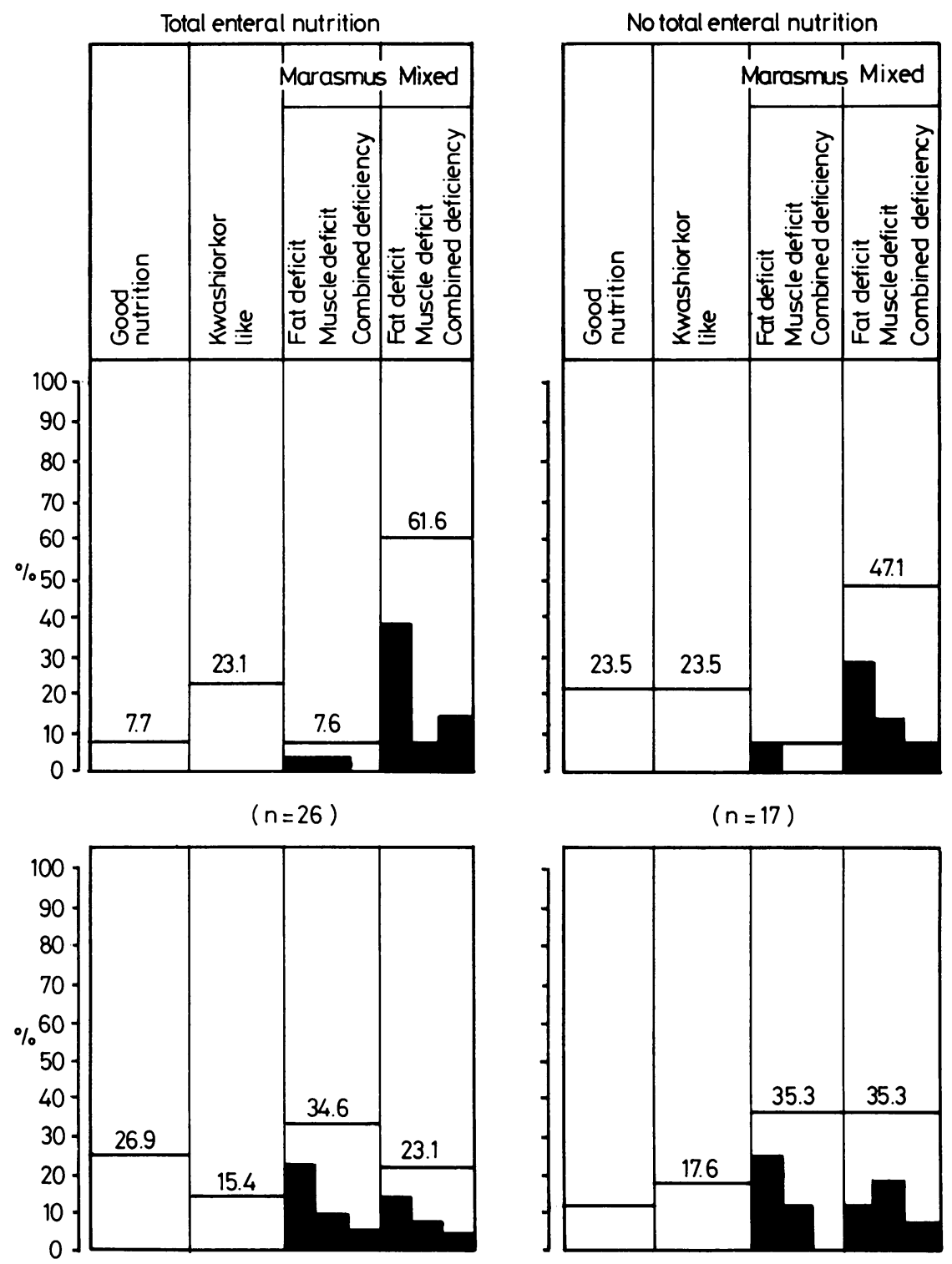

Figure Nutritional state in patients with inflammatory bowel disease. Top histograms refer to type of nutritional state on admission and histograms below to type of nutritional state at discharge.

Table Mean (SEM) increments of nutritional variables in patients receiving or not receiving enteral nutrition

\begin{tabular}{|c|c|c|c|}
\hline & $\begin{array}{l}\text { Enteral nutrition } \\
(n=26)\end{array}$ & $\begin{array}{l}\text { No enteral nutrition } \\
(n=17)\end{array}$ & $(P$ value $)$ \\
\hline \multirow{5}{*}{$\begin{array}{l}\text { Triceps skinfold thickness } \\
\text { Mid arm muscle circumference } \\
\text { Serum albumin } \\
\text { Intravenous albumin } \\
\text { (percentage of patients) }\end{array}$} & 1.0) (4.0) & $-1 \cdot 5(6 \cdot 0)$ & \\
\hline & $1.9(1.1)$ & $-7.1(1.8)$ & $<0 \cdot(0005$ \\
\hline & $20.9(4.4)$ & $14 \cdot 3(7 \cdot 4)$ & NS \\
\hline & & & \\
\hline & $21.4 \%$ & $64 \cdot 7 \%$ & $<0.01$ \\
\hline
\end{tabular}

Values refer to the incremental change expressed as a percentage of measurements obtained on admission. Mean (SEM). 
arm muscle circumference or serum albumin concentration. Fifty per cent of the group of patients who were not fed enterally before surgery required preoperative intravenous infusions of albumin compared with $18.2 \%$ of the patients fed enterally in the preoperative period. Postoperatively there was a significantly greater fall in mid arm muscle circumference in patients who did not receive enteral nutrition compared with those that did $(\mathrm{p}<0.0005)$. Again, more patients who did not receive postoperative enteral nutrition required intravenous albumin infusions than those who received enteral nutrition $(p<0 \cdot 005)$.

In the non-surgically treated patients enteral nutrition was associated with an increase in mid arm muscle circumference, whereas there was a decrease in patients who were not fed. The difference between mid arm muscle circumference in the two groups was significant $(p<0 \cdot 01)$.

When the data were analysed separately for Crohn's disease and ulcerative colitis it was found that enteral feeding in both groups was associated with significant increases in mid arm muscle circumference $(p<0.025$ or less) that did not occur in those who did not receive enteral nutrition. Enteral feeding had no significant effect on triceps skinfold thickness or serum albumin concentration. Significantly more of the patients with ulcerative colitis who did not receive enteral feeding required intravenous albumin than those who were fed enterally $(\mathrm{p}<0 \cdot 01)$.

\section{INFLUENCE OF THE NON-PROTEIN ENERGY:}

\section{NITROGEN RATIO}

In the group of patients as a whole no significant differences were seen in mid arm muscle circumference, triceps skinfold thickness, or serum albumin concentration following enteral feeding with formulations containing the high and low non-protein energy nitrogen ratios. When analysed according to gender, however, the use of the formulation with the low non-protein energy:nitrogen ratio was associated with significantly greater measurements of mid arm muscle circumference in women $(p<0.0025)$, whereas the use of the formulation with the high ratio was associated with significantly greater increments of triceps skinfold thickness in men $(\mathrm{p}<0 \cdot 05)$.

\section{Discussion}

Enteral nutrition was well tolerated in all patients. By virtue of the retrospective nature of the study design, we cannot draw conclusions as to whether enteral nutrition had a significant effect on the natural history of the exacerbations of inflammatory bowel disease. Final analysis of the data, however, did show that fewer of the patients who received enteral nutrition came to surgery $(31 \%)$ than those who did not $(47 \%)$.

While a beneficial effect of enteral nutrition on outcome cannot be proved, our findings have shown a beneficial effect on nutritional state in these patients with inflammatory bowel disease. The qualitative data summarised in the Figure show that the patients admitted with acute exacerbations of inflammatory bowel disease had a high incidence of protein energy malnutrition. Interestingly, in the patients with Crohn's disease the predominant type was mixed malnutrition. This probably reflects the long standing insidious clinical course of the underlying disease. In patients with ulcerative colitis mixed malnutrition was also seen, but there was also a significant incidence of kwashiorkor like malnutrition, in turn possibly reflecting a period of acute malnutrition and hypermetabolism that can occur in association with acute exacerbations of this disorder.

The incidence of protein energy malnutrition did not change appreciably in the group of patients who were not fed enterally. By contrast, there was a higher proportion of normally nourished patients at the end of the study in the group who received enteral nutrition in addition to standard treatment. The most consistent quantitative effect of enteral nutrition was its effect on mid arm muscle circumference. This was so in both ulcerative colitis and Crohn's disease. Mid arm muscle circumference is the nutritional variable thought to reflect muscle protein stores, and depletion occurred in patients who did not receive enteral feeding. In contrast, stores were either maintained or enhanced as a consequence of enteral feeding.

Enteral nutrition had one further consistent effect in that the necessity for intravenous albumin infusion was less in the group of patients who were fed than in those who were not.

In conclusion, our data confirm that nutritional support can be safely and effectively provided to patients with acute exacerbations of inflammatory bowel disease via the enteral route. Compared with parenteral nutrition enteral nutrition is cheaper and its use is associated with fewer complications. Recent reports suggest that enteral nutrition, using chemically defined elemental diets, may be of major therapeutic effect in Crohn's disease. ${ }^{12} 1.3$ Clearly, further controlled trials in this important area are needed.

In this study we have shown that the nutritional state of patients with ulcerative colitis can be improved by enteral feeding; whether this form of nutritional support has a major therapeutic effect in 
this condition can also only be shown by performing controlled trials.

A Abad and E Cabré were in receipt of Wander SAE and UNIASA fellowships for nutrition research, respectively.

\section{References}

1 Barot LR, Rombeau JL, Feurer ND, et al. Caloric requirements in patients with inflammatory bowel disease. Ann Surg 1982; 195: 214-18.

2 Harries A, Jones L, Heatley RV, Rhodes J. Malnutrition in inflammatory bowel disease: an anthropometric study. Hum Nutr 1982; 36C: 279-84.

3 Heimann T, Gelernt I, Schanzer H, et al. Surgical treatment, skin test reactivity and lymphocytes in inflammatory bowel disease. Am J Surg 1983; 145: 199-201.

4 Higgens CS, Keighley MRB, Allan ERN. Impact of preoperative weight loss and body composition changes on postoperative outcome in surgery for inflammatory bowel disease. Gut 1984; 25: 732-6.

5 Reilly J. Inflammatory bowel disease. In: Fischer JG, ed. Total parenteral nutrition. Boston: Little Brown \& Co. 1976; 187-202.

6 Beeken WL, Baseh HJ, Sylvester D. Intestinal protein loss in Crohn's disease. Gastroenterology 1971; 62: 207-15.

7 Powell-Tuck J, Garlich PJ, Lennard-Jones JE, Waterlow JC. Rates of whole body protein synthesis and breakdown increase with the severity of inflammatory bowel disease. Gut 1984; 25: 460-4.
8 Clark ML. Role of nutrition in inflammatory bowel disease - an overview. Gut 1986; 27 (Suppl): 72-5.

9 Matuchansky C. Parenteral nutrition in inflammatory bowel disease. Gut 1986;

10 Harper PH, Lee ECG, Kettlewell MGW, et al. Role of the faecal stream in the maintenance of Crohn's colitis. Gut 1985; 26: 279-84.

11 Lochs H, Meryn S, Marosi L, et al. Has total bowel rest a beneficial effect in the treatment of Crohn's disease? Clin Nutr 1983; 2: 61-4.

12 O'Morain C, Segal AW, Levi AJ. Elemental diets in the treatment of acute Crohn's disease. Br Med J 1980; 281: 1173-5.

13 O'Morain C, Segal AW, Levi AJ. Elemental diet as primary treatment of acute Crohn's disease. A controlled trial. Br Med J 1984; 288: 1859-62.

14 Goode A, Hawkins T, Faggetter JGW, Johnston IDA. Use of an elemental diet for long term nutritional support in Crohn's disease. Lancet 1976; i: 122-4.

15 Morin CL, Roulet M, Roy CC, Weber A. Continuous elemental enteral alimentation in children with Crohn's disease and growth failure. Gastroenterology 1980; 79: 1205-10.

16 Kirschner BS, Klich JR, Kalmen SS, et al. Reversal of growth retardation in Crohn's disease with therapy emphasising oral nutritional restitution. Gastroenterology 1981; 80: 10-15.

17 Gassull MA, Cabre E, Vilar L, Alastrue A, Montserrat A. Protein-energy malnutrition. An integral approach and a simple new classification. Hum Nutr Clin Nutr 1984; 38C: 419-31.

18 Jones BJM, Payne S, Silk DDA. Indications for pump-assisted enteral feeding. Lancet 1980; i: 1057-8. 